\title{
Roughness indices for estimation of depression storage capacity of tilled soil surfaces
}

\author{
Bjarne Hansen*, Per Schjønning, Erik Sibbesen ${ }^{1}$ \\ Department of Crop Physiology and Soil Science, Research Centre Foulum, Danish Institute of Agricultural Sciences, \\ PO Box 50, DK-8830 Tjele, Denmark
}

Received 29 June 1998; received in revised form 24 February 1999; accepted 16 June 1999

\begin{abstract}
Information on the depression storage capacity (DSC) of soil surfaces is needed for modelling surface runoff and erosion. However, time-consuming measurements of the soil surface microrelief in a two-dimensional grid are necessary to obtain accurate estimates. Therefore, estimation of DSC from roughness indices requiring fewer measurements is desirable. In this study a new simple and physically based roughness index was developed and tested. Thirty-two soil surface microreliefs were determined in Danish erosion study plots on two sandy loam soil types, Humic Acrosol and Haplic Luvisol according to the FAO soil classification. The soil treatments were: cultivated up-and-down the slope (black fallow), mouldboard ploughed upand-down the slope, winter wheat (Triticum aestivum L.) drilled up-and-down the slope and winter wheat drilled across the slope. The slope was ca. $10 \%$ for all plots. Data were treated initially by removing the slope after which 20 artificial slopes (120\%) were introduced producing 640 data sets. The DSC was calculated for each data set and a number of roughness indices were related to the calculated DSC. The best correlation to DSC was obtained by the newly developed index, mean upslope depression, MUD $\left(R^{2}=0.86\right)$, followed by the geostatistically based limiting elevation difference, LD, and limiting slope, LS $\left(R^{2}=0.76\right)$, and some statistically based parameters as standard deviation adjusted for oriented roughness up-and-down the slope $\left(R^{2}=0.76\right)$, random roughness, $\mathrm{RR}\left(R^{2}=0.67\right)$, and standard deviation adjusted for oriented roughness both up-anddown and across the slope $\left(R^{2}=0.62\right)$. Furthermore, MUD appeared to give less biased estimates than other indices, which overestimated small DSC-values and underestimated larger DSC-values. Calculations showed that the MUD index required relatively few measurements. MUD based on less than 200 surface elevation readings gave a good prediction $\left(R^{2}>0.7\right)$ of DSC of tilled soil surfaces. (C) 1999 Elsevier Science B.V. All rights reserved.
\end{abstract}

Keywords: Depression storage; Surface roughness; Roughness index; Surface runoff; Microrelief; Surface topography

\section{Introduction}

Soil surface roughness affects the depressional storage capacity (DSC) for ponding water and thereby

*Corresponding author. Tel.: +45-89-99-19-00; fax: +45-89-9916-19

E-mail address: bjarne.hansen@agrsci.dk (B. Hansen)

${ }^{1}$ Erik Sibbesen died on 23 October 1998. the conditions for surface runoff and soil erosion. The DSC is also affected by the slope steepness. Generally rougher surfaces store more surface water than 
smoother surfaces and steeper slopes store less surface water than gentle slopes (Moore and Larson, 1979; Ullah and Dickinson, 1979a, b; Onstad, 1984).

On agricultural land the soil surface roughness is mainly influenced by tillage, vegetation, soil type and previous amount and intensity of rainfall (Allmaras et al., 1966; Burwell and Larson, 1969; Zobeck and Onstad, 1987). Soil surface roughness is also influenced by less dominant factors such as the amount of runoff, freeze-thaw cycles, and wind (Gayle and Skaggs, 1978).

Computer models for calculating DSC and surface runoff for a plot based on grid elevation measurements have been developed by Moore and Larson (1979) and Onstad (1984). Based on the slope and the random roughness index (RR) as defined by Allmaras et al. (1966), Onstad (1984) developed transfer functions for estimating DSC, the soil surface fraction covered by water, and rainfall needed to initiate surface runoff.

For calculating the RR-index or DSC with such models, surface elevation data on a detailed grid are needed. However, obtaining such data is time-consuming so methods for estimating DSC from roughness indices requiring less data would be valuable. The objective of this study was to develop and test roughness indices for estimating DSC and further to assess the amount of elevation data needed to obtain reliable estimates, for two soil types in Denmark.

\section{Existing indices for quantification of soil surface roughness}

Most of the indices used for quantification of soil surface roughness have been based on the standard deviation of height measurements. The RR index described by Allmaras et al. (1966) is the most frequently quoted roughness index. It is calculated from surface elevation data in a grid as follows:

1. All elevation data are transformed to natural logarithm.

2. Contributions from the oriented roughness and slope are then eliminated by correcting each elevation point for the deviation of the mean elevation height of its row and column and the mean elevation height of all elevation points.
3. The $10 \%$ upper and lower extreme values are subsequently excluded from the data set.

4. The RR is then obtained as the product of the standard deviation of the remaining logarithmic transformed data and the overall arithmetic mean.

Many authors claim to calculate RR according to Allmaras et al. (1966) or Burwell et al. (1963). However, it seems that RR has often been computed as the standard deviation among height measurements, that the height measurements have not been converted to natural logarithms or that the adjustments for slope, unusually high or low values, or oriented roughness have not been made.

An index such as RR is purely statistically based. Linden and Van Doren, 1986 defined two surface configuration parameters, limiting slope (LS) and limiting elevation difference (LD) based on geostatistics and especially considering the relation between neighbouring grid points. These two indices are directly related to the configuration of the surface and are also sensitive to differences in roughness.

Calculation of LS and LD are based on the mean absolute elevation difference, $\Delta Z_{h}$, defined as

$$
\Delta Z_{h}=\sum_{i=1}^{n} \frac{\left|Z_{i}-Z_{i+h}\right|}{n},
$$

where $Z_{i}$ is the elevation of a point and $Z_{i+h}$ the elevation of a point some lag number, $h$, from the point $Z_{i}$. The relationship between $\Delta Z_{h}$ and the lag distance, $\Delta X_{h}$, was obtained from a linear regression of their reciprocals:

$$
1 / \Delta Z_{h}=a+b\left(1 / \Delta X_{h}\right),
$$

where $a$ and $b$ are fitted constants. The horizontal spacing $\Delta X_{h}$ was limited to a maximum of $20 \mathrm{~cm}$. The reciprocals of the constants $a$ and $b$, were designated limiting elevation difference, LD, and limiting slope, LS, respectively, i.e.,

$$
\begin{aligned}
\mathrm{LD} & =1 / a, \\
\mathrm{LS} & =1 / b .
\end{aligned}
$$

Linden et al. (1988) found that the best index for predicting DSC was a combination of the LD and LS roughness indices defined as $(\mathrm{LD} * \mathrm{LS})^{1 / 2}$. The LD and LS indices are physically based. However, the regressions involved in these calculations to some 
extent neglect important characteristics of the soil surface as reflected in the exact difference in level between adjacent grid points. Simpler indices, also taking into account the relation between neighbouring grid points, might produce the same or better correlation to DSC.

In this study a new physically based depression storage index was developed and compared with the indices mentioned above.

\section{Materials and methods}

\subsection{Surface roughness data}

Surface roughness data were obtained from erosion study plots located at Foulum and Ødum in Denmark. The Foulum topsoil contains $88 \mathrm{~g} \mathrm{~kg}^{-1}$ clay $(<2 \mu \mathrm{m})$ and $356 \mathrm{~g} \mathrm{~kg}^{-1}$ fine sand $(20-200 \mu \mathrm{m})$, while the Ødum topsoil contains $106 \mathrm{~g} \mathrm{~kg}^{-1}$ clay and $436 \mathrm{~g} \mathrm{~kg}^{-1}$ fine sand (Schjønning et al., 1995; Hansen et al., 1996). Both locations are situated on morainic deposits from the Weichselian Ice Period. The Foulum soil can be classified as a Typic Hapludult or Humic Acrisol and the Ødum one as a Typic Agrudalf or Haplic Luvisol according to the USDA Soil Taxonomy System (Anon., 1975) or the FAO soil classification (FAO, 1994), respectively.

Soil surface roughness was measured by means of an automated surface relief meter (Schjønning, 1993). Surface elevations were measured in a grid $258 \mathrm{~cm}$ wide (across slope) and $132 \mathrm{~cm}$ long (along slope). The spacing between the recordings was $6 \mathrm{~cm}$ across and $3 \mathrm{~cm}$ along totalling 45 lines across and 44 lines along the slope.

Thirty-two independent data sets were obtained, with eight from each of the following treatments: cultivated up-and-down the slope (black fallow), mouldboard ploughed up-and-down the slope, winter wheat (Triticum aestivum L.) drilled up-and-down the slope and winter wheat drilled across the slope. Schjønning et al. (1995) provide a detailed description of soil treatments. Half of the measurements were made late autumn and half early spring before seed bed preparation of the mouldboard ploughed plots.

The slope was about $10 \%$ for all plots. However, slope is an important parameter in calculating DSC and different slopes were necessary in this study. Therefore, different 'artificial' slopes were added to the measured data. First the slope was removed from the 32 original data sets. A plane of best fit was calculated for each data set by multiple regression. Row and column positions were used as independent variables and the height readings represented the dependent variable. The residuals were used as the new height readings. Afterwards the mean elevations of rows across the slope were adjusted to give mean slopes from $1 \%$ to $20 \%$ in steps of $1 \%$. These adjustments did not affect the roughness or the elevation variations within rows across the slope. In this way 640 new data sets with varying slope were obtained.

\subsection{Depression storage capacity}

A computer model was developed in Turbo Pascal (Borland International) to calculate DSC from grid elevation data similar to the models of Moore and Larson (1979) and Onstad (1984). Drainage direction was allowed towards both the four corners and the four sides of each element as in Onstad's model. The eight possible drainage directions give a slightly less depressional storage (Onstad, 1984) than the model of Moore and Larson (1979), which allowed drainage only towards the four sides of each element. The model allows runoff in one or more directions from the plot. Input to the programme is grid elevation data, number of lines up-and-down the slope, number of readings per line, distance between lines, and distance between readings on the line.

The DSC was calculated from grid elevation data for each of the 640 data sets. Runoff downwards and sideways from the plot was allowed in the calculations. These boundary conditions are expected to be closest to field conditions.

\subsection{Surface roughness indices}

A new physically based index of surface roughness was developed and tested. It is based on the elevation differences $\left(Z_{\mathrm{r}}-Z_{\mathrm{a}}\right)$ between a reference point $\left(X_{\mathrm{r}}\right)$ and points $\left(X_{\mathrm{a}}\right)$ on a line segment positioned upslope from the reference point. Within each line segment, the calculation procedure is iterated for a number of subsegments (see Fig. 1), each time taking a new upslope 


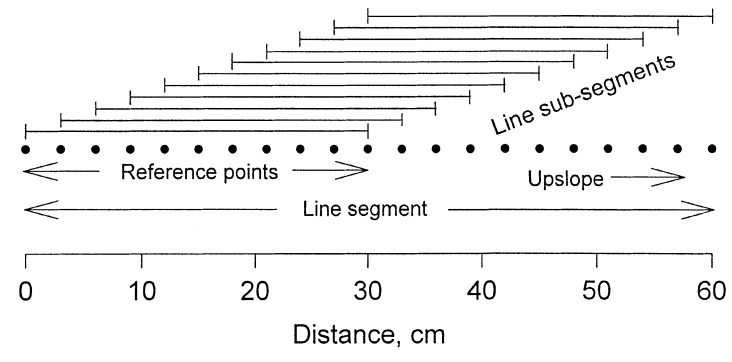

Fig. 1. A sketch of the principle for calculation of the MUD-index from reference points and sub-segments in a line segment. Exemplified for the up-and-down slope situation.

point as the reference point:

$$
\operatorname{MUD}=\sum_{i=1}^{m}\left(\sum_{j=1}^{n} \Delta Z / n\right) / m,
$$

where $\Delta Z=Z_{\mathrm{r}}-Z_{\mathrm{a}}$ for $Z_{\mathrm{a}}<Z_{\mathrm{r}} ; \Delta Z=0$ for $Z_{\mathrm{a}} \geq Z_{\mathrm{r}} ; n$ is the number of points in a line sub-segment and $m$ is the number of line sub-segments.

In this way the elevation difference between the reference point and points with a lower elevation (surface depressions relative to the reference point) in a line sub-segment is summed up and divided by the number of points, i.e., the index expresses the mean upslope depressions (MUD) relative to the reference point. Several independent line segments will normally contribute to this mean value. The MUD index reflects both the surface roughness and the slope. If the slope increases then the MUD decreases, i.e., the slope is 'integrated' in the MUD index.

As for calculation of the LD and LS parameters the horizontal spacing, i.e., length of sub-segments, should be limited. A length of $30 \mathrm{~cm}$ was used as calculations showed that best correlation between MUD and DSC was obtained with length of subsegments between 27 and $33 \mathrm{~cm}$.

The roughness oriented up-and-down a slope affects the DSC more than the roughness oriented across the slope, as will be shown later. Therefore, readings upand-down the slope are the most important. However, the DSC also depends on the roughness across the slope. Therefore, the highest correlation was obtained if calculations were made for both directions. The MUD calculated up-and-down the slope is denoted $\mathrm{MUD}_{\mathrm{u}}$ and MUD across is denoted MUD $\mathrm{a}$ in the following.
The LD and LS parameters as suggested by Linden and Van Doren, 1986, and the suggested $\mathrm{MUD}_{\mathrm{u}}$ and MUD $_{\mathrm{a}}$ were calculated and tested as predictors of DSC. Furthermore, the following four statistically based indices of soil surface roughness were included in the comparisons.

RE1 is the standard deviation of height readings after correction for slope; RE2 is the same as RE1 but adjusted for oriented roughness up-and-down the slope; RE3 is the same as RE1 but adjusted for oriented roughness up-and-down and across the slope and RR is the random roughness according to Allmaras et al. (1966).

\section{Results and discussions}

Examples of surface relief before adjusting for slope are shown in Fig. 2. The RR of the 32 data sets ranged from 3.5 to $13.1 \mathrm{~mm}$, which indicates that the surfaces were relatively smooth. Onstad (1984) found RR from 4 to $60 \mathrm{~mm}$, Currence and Lovely (1970) from 3.2 to $33 \mathrm{~mm}$ and Zobeck and Onstad (1987) from 7 to $50 \mathrm{~mm}$.

\subsection{Relations between roughness parameters and depression storage capacity}

A multiple regression including only slope and slope squared as independent parameters accounted for $46 \%$ of the variation in DSC, Eq. (6) (Table 1). If standard deviations of height readings adjusted for slope only (RE1) were included, the $R^{2}$ value increased slightly, Eq. (7), but if the readings were adjusted for oriented roughness up-and-down the slope (RE2), $R^{2}$ increased to 0.76, (Eq. (8)). Additional adjustments for oriented roughness across the slope (RE3) decreased $R^{2}$ to 0.62 , Eq. (9). If standard deviation of height readings is used to estimate DSC, then apparently readings should be adjusted for oriented roughness up-and-down but not across the slope as in e.g., RR. Alternatively the readings should be taken in lines up-and-down the slope only. RR seems to be slightly better correlated with DSC than RE3, Eqs. (9) and (10).

Onstad (1984) found $R^{2}=0.82$ for the model tested in Eq. (11) compared to $R^{2}=0.60$ for this investigation. One of the reasons is a different variation of $R R$. 

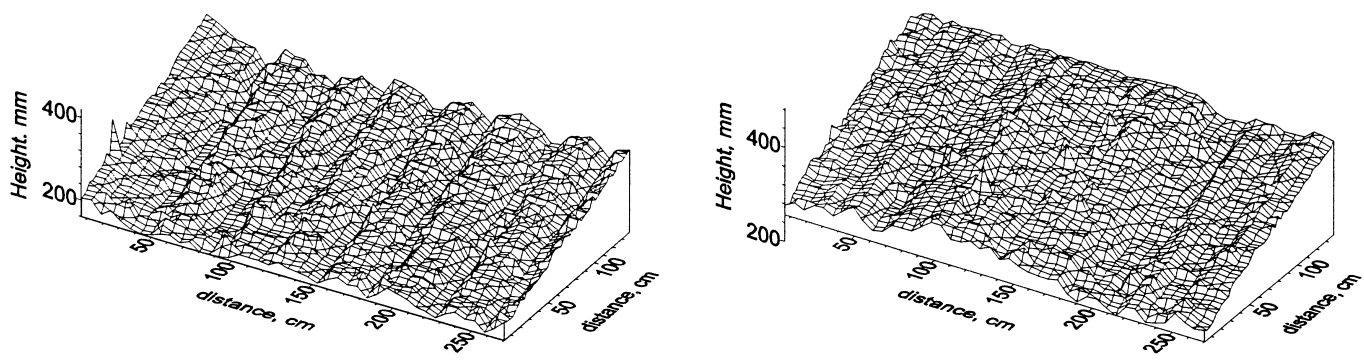

Cultivated (fallow)

Wheat drilled up-and-down the slope

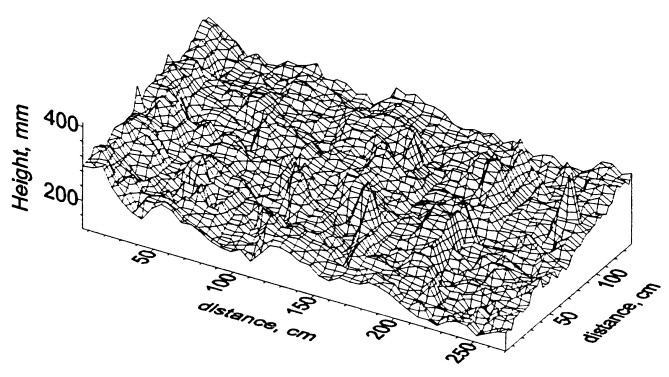

Ploughed

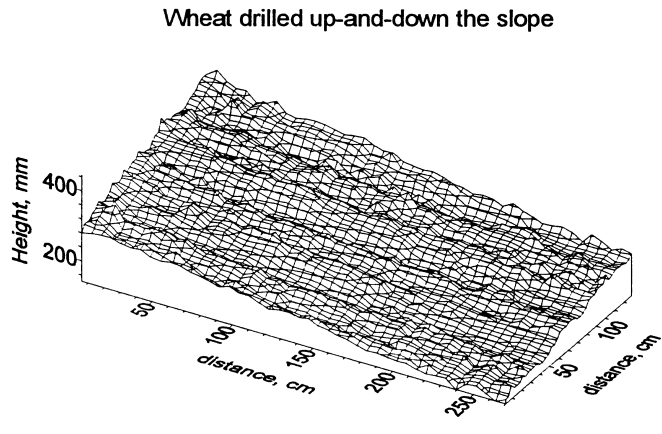

Wheat drilled across the slope

Fig. 2. Examples of surface relief data before adjusting for slope. Note different scales on horizontal and vertical axes.

However, the present data showed clearly that the relation between DSC and slope was not linear as Eq. (11) indicates and the main reason for the different $R^{2}$ is probably a wider range of slopes in the present data.

The models involving the geostatistically based LD and LS parameters explained more of the variation in the data set than did the RR-index (Table 1). This is in accordance with Linden et al. (1988). However, even the best of these models (Eq. (12)) only slightly increased $R^{2}$ compared to the RE2-parameter involving only standard deviation adjusted for up-anddown slope roughness (Eq. (8)).

Mean upslope depressions calculated for up-anddown slope lines only $\left(\mathrm{MUD}_{\mathrm{u}}\right)$ accounted for $80 \%$ of the variation in DSC (Table 1, Eq. (15)). The slope is

Table 1

Regression equations relating DSC $(\mathrm{mm})$ to roughness indices $(\mathrm{mm})$ and slope $(\mathrm{m} / \mathrm{m})$

\begin{tabular}{|c|c|c|c|}
\hline \multicolumn{2}{|l|}{ Regression equation } & \multirow{2}{*}{$\frac{R^{2}}{0.463}$} & \multirow{2}{*}{$\frac{\text { C.V. }}{67.6}$} \\
\hline $2.51-25.0 \times S+73.3 \times S^{2}$ & (6) & & \\
\hline $0.133 \times \mathrm{RE} 1-1.32 \times \mathrm{RE} 1 \times S+3.89 \times \mathrm{RE} 1 \times S^{2}$ & (7) & 0.477 & 67.2 \\
\hline $0.203 \times \mathrm{RE} 2-2.07 \times \mathrm{RE} 2 \times S+6.13 \times \mathrm{RE} 2 \times S^{2}$ & (8) & 0.760 & 46.1 \\
\hline $0.228 \times \mathrm{RE} 3-2.31 \times \mathrm{RE} 3 \times S+6.83 \times \mathrm{RE} 3 \times S^{2}$ & (9) & 0.622 & 57.9 \\
\hline $0.369 \times \mathrm{RR}-3.76 \times \mathrm{RR} \times S+11.1 \times \mathrm{RR} \times S^{2}$ & $(10)$ & 0.669 & 54.1 \\
\hline $0.261 \times \mathrm{RR}-1.43 \times \mathrm{RR} \times S+0.00032 \times \mathrm{RR}^{2}$ & (11) & 0.599 & 59.6 \\
\hline $0.173 \times \mathrm{LD}-1.78 \times \mathrm{LD} \times S+5.29 \times \mathrm{LD} \times S^{2}$ & (12) & 0.764 & 45.7 \\
\hline $0.837 \times Q-8.53 \times Q \times S+25.2 \times Q \times S^{2}$ & (13) & 0.711 & 54.7 \\
\hline$-0.77-3.37 \times Q \times S+0.941 \times Q$ & (14) & 0.636 & 56.7 \\
\hline $0.480 \times \mathrm{MUD}_{\mathrm{u}}$ & $(15)$ & 0.797 & 42.2 \\
\hline $0.224 \times \mathrm{MUD}_{\mathrm{u}}+2.14 \times \mathrm{MUD}_{\mathrm{u}} / \mathrm{MUD}_{\mathrm{a}}$ & (16) & 0.858 & 35.6 \\
\hline
\end{tabular}

For explanation of roughness indices see text, Section 3.3.

$S:$ slope; $Q=(\mathrm{LD} \times \mathrm{LS})^{1 / 2}$. 


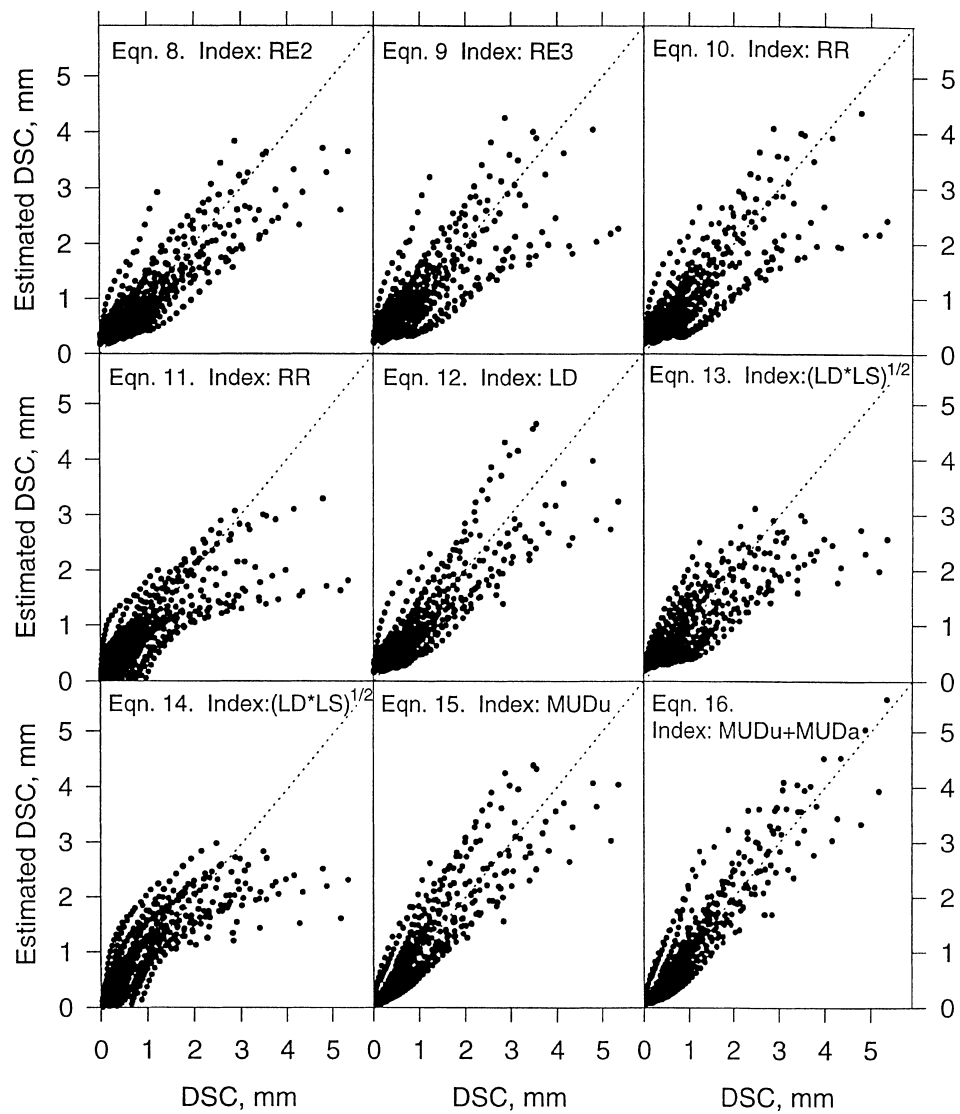

Fig. 3. Measured and estimated depression storage capacity, DSC. Equations are from Table 1.

not included as an independent variable in this model as it is 'integrated' in the MUD parameter. The tendency of surface water to flow across the slope can be accounted for by the ratio $\mathrm{MUD}_{\mathrm{u}} / \mathrm{MUD}_{\mathrm{a}}$. When including this quotient, nearly $86 \%$ of the variation in DSC was accounted for (Table 1, Eq. (16)).

Plots of estimated versus measured DSC values are shown in Fig. 3. Some of the estimated values seem to be biased, especially at high DSC values, where DSC is underestimated. The DSC estimated by MUD-parameters seems to be less biased than others (Fig. 3).

\subsection{Sample size requirements}

The regression analyses included all data in the data sets. The advantage of using roughness indices for estimating DSC is that they require less data than calculating DSC from a grid. However, it is essential to know the necessary sample size requirements for estimating the parameters.

Various numbers of line segments of 30, 45, 60, 90 and $120 \mathrm{~cm}$ length along and across the slope were randomly chosen in each of the 640 data sets and used for estimating DSC by means of the MUD ${ }_{u}$ and MUD parameters and the Eqs. (15) and (16) (Table 1). The correlation between those DSC-values and DSC calculated from the grid is shown in Fig. 4.

To achieve an $R^{2}>0.7$ for measurements up-anddown the slope (Eq. (15)), only 5 line segments of $120 \mathrm{~cm}$ length, 7 line segments of $90 \mathrm{~cm}$ length or 12 line segments of $60 \mathrm{~cm}$ length were required including 205, 217 and 252 grid points, respectively. Similarly, for measurements both up-and-down and across the slope (Eq. (16)) the required number of line segments of 120, 90 and $60 \mathrm{~cm}$ were 3, 4 and 8 including 186, 

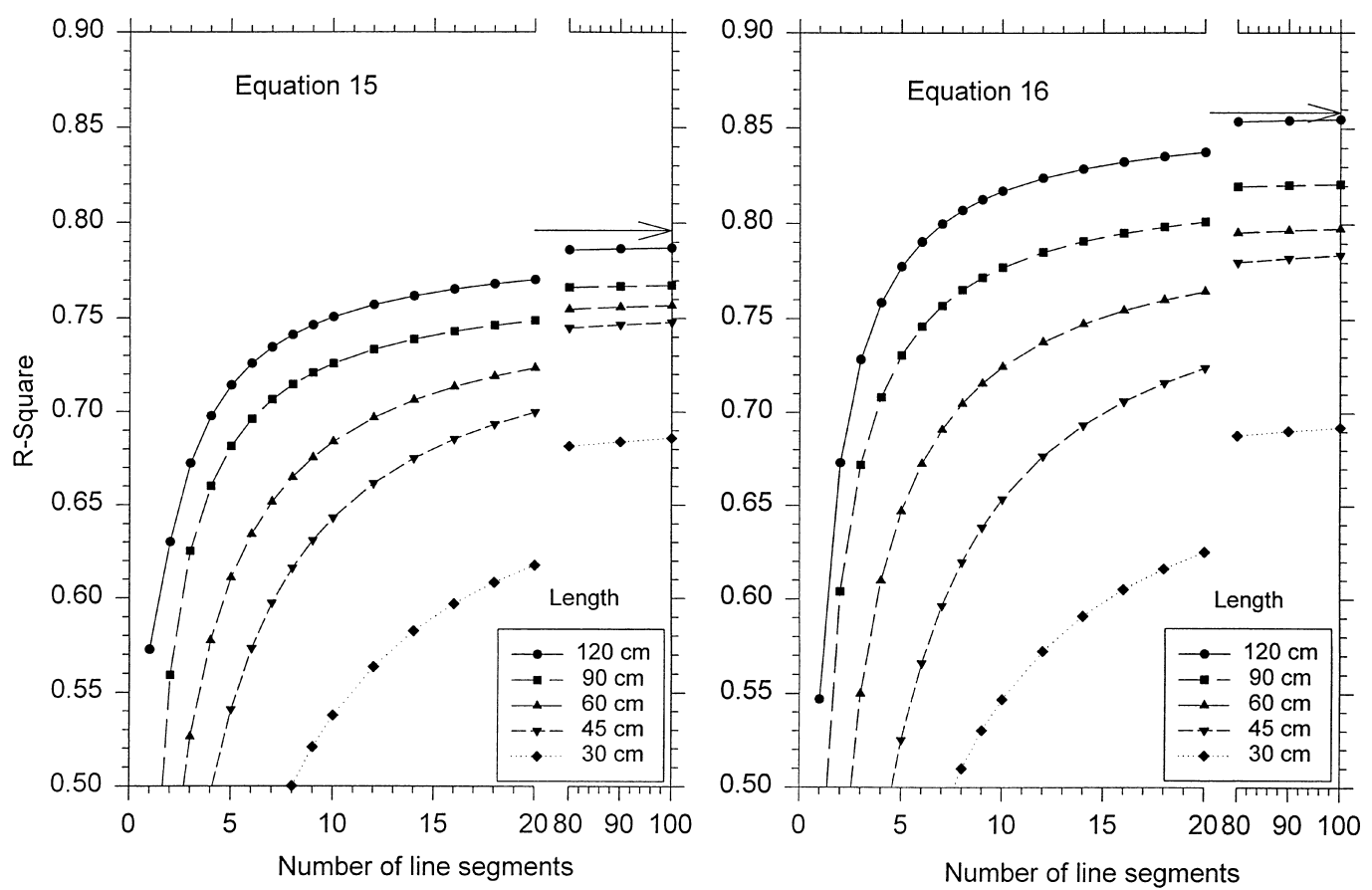

Fig. 4. Correlation between DSC measured and estimated with the MUD using Eq. (15) (up-and-down the slope) and Eq. (16) (up-and-down and across the slope) for different numbers and lengths of line segments. Arrows point out the model explanation when all data were used for the estimation.

188 and 256 grid points, respectively. As expected, line segments covering a distance of $30 \mathrm{~cm}$ are not efficient, because only one of eleven grid points could be used as a reference point for a $30 \mathrm{~cm}$ sub-segment. Based on the number of grid points it seems that the longest distances are the most efficient.

The grid data available with spacing of 3 and $6 \mathrm{~cm}$ did not allow a test of the influence of distance between grid points. However, some data measured with a pinmeter were available (Iversen, unpublished). Each measurement included 150 points spaced $1 \mathrm{~cm}$ apart on a line. Calculations based on these data indicated that the calculated MUD-value was almost independent of the distance between the measured points if the distance did not exceed some maximum, which depended on the surface roughness and the slope. If the elevation difference between neighbouring points caused by the slope exceeded 5-10\% of the roughness, calculated as the standard deviation of residuals from a regression line, then the calculated MUD-value decreased.

\subsection{Calculation of MUD from field measurements}

If height measurements have been performed for a number of line segments in a field, the MUD-index should be calculated for each segment according to Eq. (5). If all line segments were equally sloped, an average MUD-index can be derived directly from these data. However, as slope is an integrated part of the MUD-index, calibration to identical slopes should be performed if the line segments in the field had different slopes (as is most often the case). This is achieved by first calculating the slope from linear regression for each line segment, taking the horizontal positions as independent and height readings as dependent variables. Afterwards MUD-indices for different slopes can be calculated from 'calibrated' height readings, created by adding the residuals from the regression to the specific slopes.

In Fig. 5, MUD is shown as a function of slope for the four data sets presented in Fig. 2. The MUD dependency of slope was described fairly well by a regression equation with slope and slope squared as 


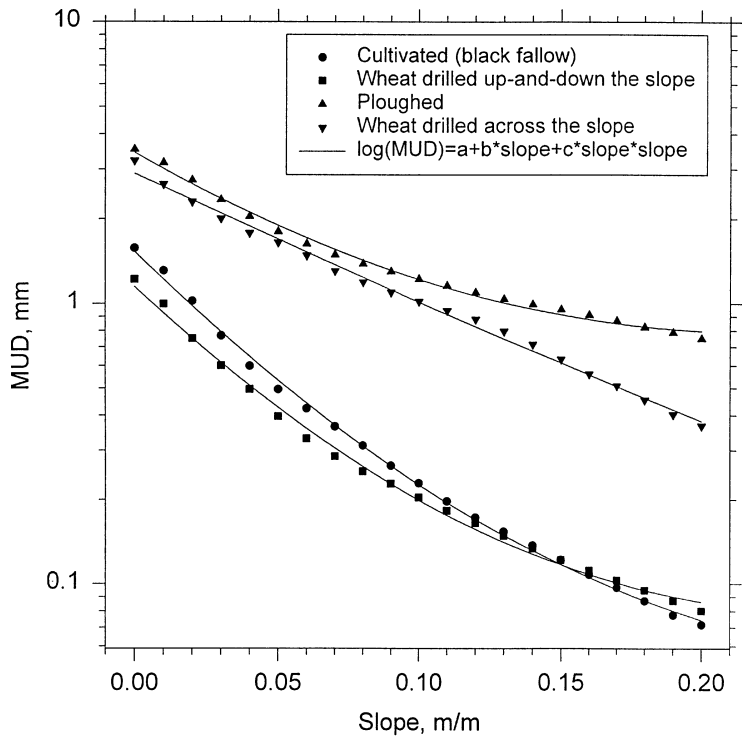

Fig. 5. MUD as related to slope for the data displayed on Fig. 2.

independent and the logarithm of MUD as dependent variables (Fig. 5). Similar to this, for any area in investigation, estimates of MUD for slopes relevant for the area can be derived from height measurements in a few line segments.

\section{Conclusions}

Regression analyses have shown that the best of several tested roughness indices for predicting DSC was a newly developed index called mean upslope depression (MUD). The correlation was highest and the estimated DSC was less biased compared to estimates based on other parameters. The MUD calculated for up-and-down slope lines accounted for $80 \%$ of the variation in DSC. If MUD calculated for lines across the slope was added the model prediction increased to nearly $86 \%$ of the variation in DSC observed.

Relatively few measurements are necessary for estimating MUD. For measurements up-and-down the slope only 5 line segments of $120 \mathrm{~cm}$ length, 7 line segments of $90 \mathrm{~cm}$ length or 12 line segments of $60 \mathrm{~cm}$ length were required to account for $70 \%$ of the variation in DSC. For measurements both up-anddown and across the slope the required number of line segments to achieve the $70 \%$ prediction precision were 3,4 and 8 , respectively.

If standard deviation of height readings is used to estimate DSC, then apparently readings should be adjusted for oriented roughness up-and-down but not across the slope as in e.g., RR. Alternatively the readings should be taken in lines up-and-down the slope only.

The grid size was governed by the data available and a possible effect of grid size could not be tested. However, the calculated MUD-values seemed almost independent of the distance between measured points if the distance did not exceed a maximum dependent on the surface roughness and the slope.

\section{References}

Allmaras, R.R., Burwell, R.E., Larson, W.E., Holt, R.F., 1966. Total porosity and random roughness of the interrow zone as influenced by tillage. USDA, Conservation Research Report no. 7, $22 \mathrm{pp}$.

Anon, 1975. Soil Taxonomy. A basic system for soil classification for making and interpreting soil surveys. USDA Agricultural Handbook no. 436, US Government Press, Washington, DC.

Burwell, R.E., Allmaras, R.R., Amemiya, M., 1963. A field measurements of total porosity and surface microrelief of soils. Soil Sci. Soc. Am. Proc. 27, 697-700.

Burwell, R.E., Larson, W.E., 1969. Infiltration as influenced by tillage-induced random roughness and pore space. Soil Sci. Soc. Am. Proc. 33, 449-452.

Currence, H.D., Lovely, W.G., 1970. The analysis of soil surface roughness. Trans. ASAE. 13, 710-714.

FAO, 1994. Soil map of the world. Technical Paper 20. Reprint of World Soil Resources Report 60, FAO, Rome, 1988. Reprint with corrections, 1990. ISRIC, Wageningen.

Gayle, G.A., Skaggs, R.W., 1978. Surface storage on bedded cultivated lands. Trans. ASAE 21, 101-104, 109.

Hansen, B., Sibbesen, E., Schjønning, P., Thomsen, A., Hasholt, B., 1996. Surface runoff, erosion and loss of sediment and phosphorus - Danish plot studies. In: Kronvang, B., Svendsen, L.M., Sibbesen, E. (Eds.), Phosphorus and Sediment. Erosion and Delivery, Transport and Fate of Sediment and SedimentAssociated Nutrients in Watersheds. Proceedings from an International Workshop in Silkeborg, Denmark, October 9-12, 1995. NERI Technical Report No. 178, pp. 29-32.

Linden, D.R., Van Doren, D.M., 1986. Parameters for characterizing tillage-induced soil surface roughness. Soil Sci. Soc. Am. J. 50, 1560-1565.

Linden, D.R., Van Doren, D.M., Allmaras, R.R., 1988. A model of the effects of tillage-induced soil surface roughness on erosion. Proceedings of the 11th International Conference of the International Soil and Tillage Research Organization, Edinburgh, 1, pp. 373-378. 
Moore, I.D., Larson, C.L., 1979. Estimating microrelief surface storage from point data. Trans. ASAE. 20, 1073-1077.

Onstad, C.A., 1984. Depressional storage on tilled soil surfaces. Trans. ASAE. 27, 729-732.

Schjønning, P., 1993. An automated surface profile meter. Department note no. 13. Danish Institute of Plant and Soil Science. Department of Soil Physics, Soil Tillage and Irrigation, $10 \mathrm{pp}$. (unpublished).

Schjønning, P., Sibbesen, E., Hansen, A.C., Hasholt, B., Heidmann, T., Madsen, M.B., Nielsen, J.D., 1995. Surface runoff, erosion and loss of phosphorus at two agricultural soils in Denmark - plot studies 1989-92. SP-report no. 14, 1995. Danish Institute of Plant and Soil Science, 196 pp.

Ullah, W., Dickinson, W.T., 1979a. Quantitative description of depression storage using a digital surface model. I. Determination of depression storage. J. Hydrol. 42, 63-75.

Ullah, W., Dickinson, W.T., 1979b. Quantitative description of depression storage using a digital surface model. II. Characteristics of surface depressions. J. Hydrol. 42, 77-90.

Zobeck, T.M., Onstad, C.A., 1987. Tillage and rainfall effects on random roughness: a review. Soil Tillage Res. 9, 1-20. 